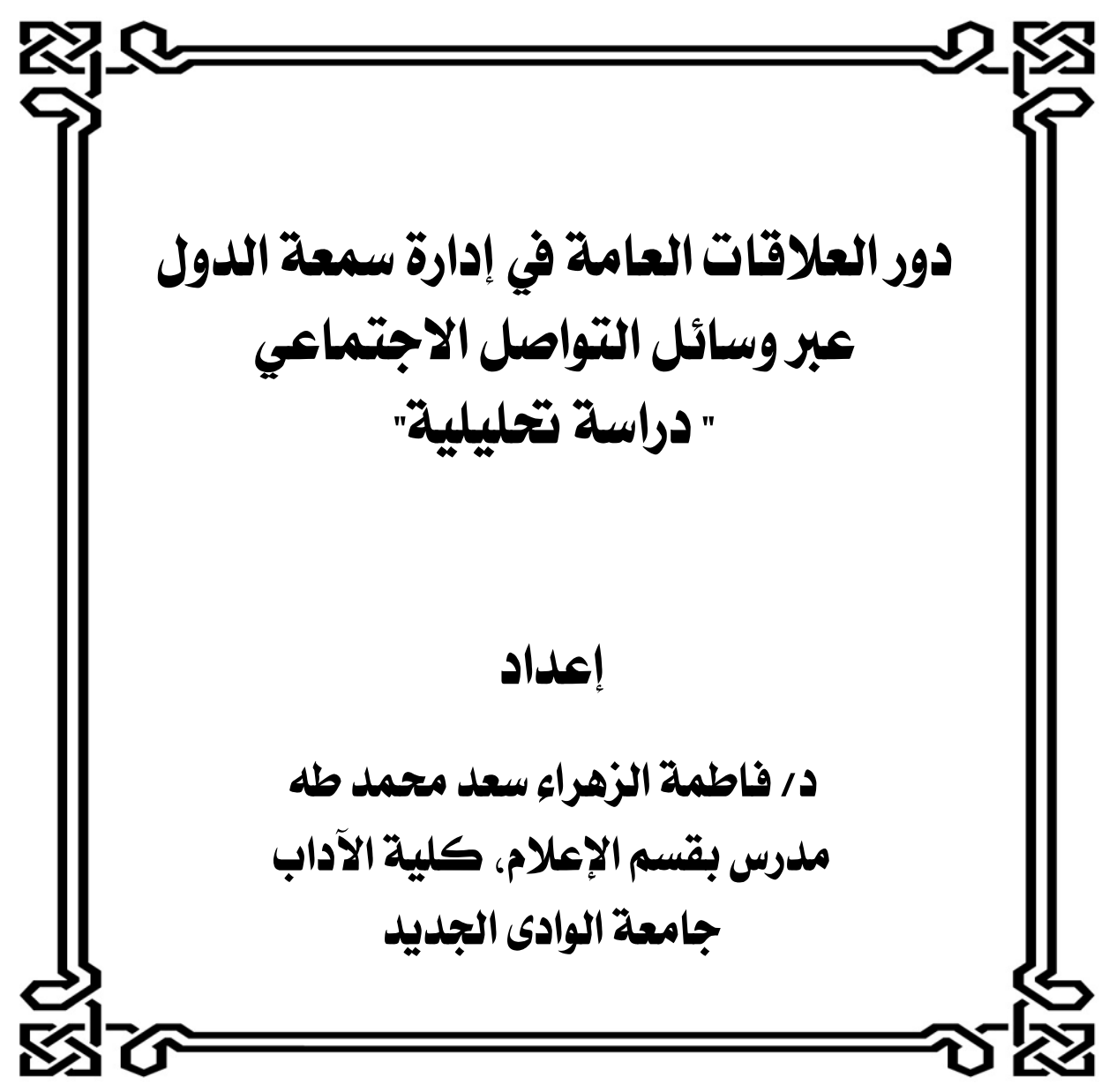


فاطمة الزهر اءء سعد محمد طه دور العلاقات العامة في إدارة سمعة الدول عبر

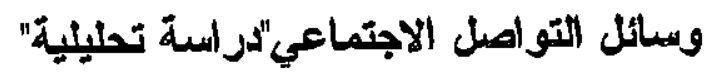
$=\frac{9}{10}$

مقدمة

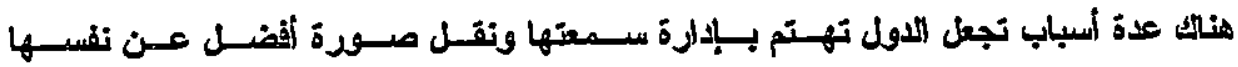

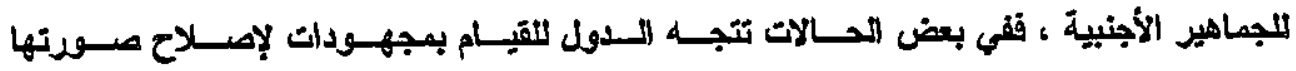

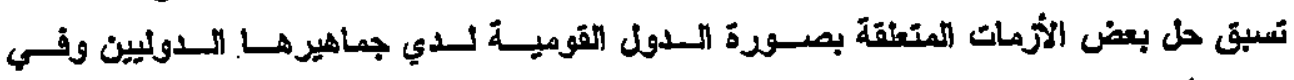

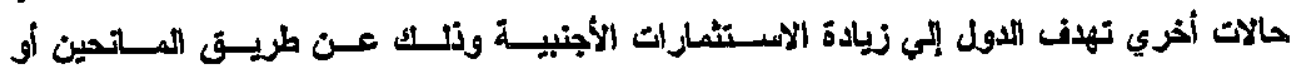

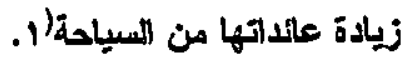

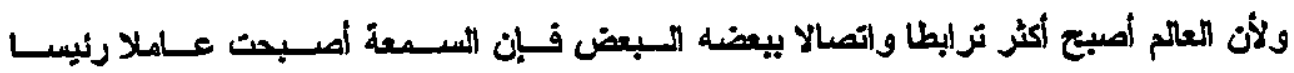

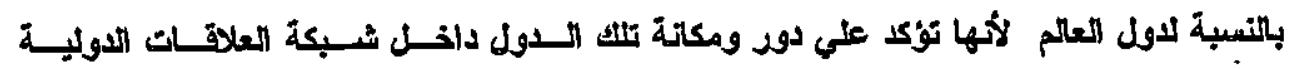

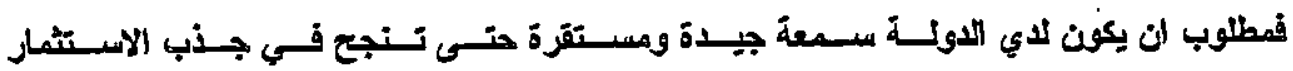

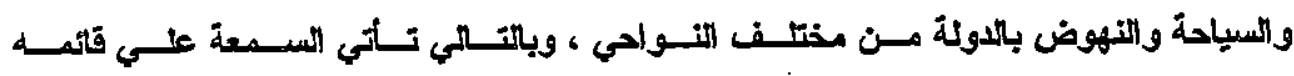

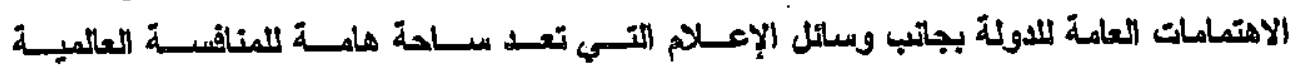

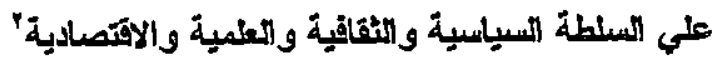

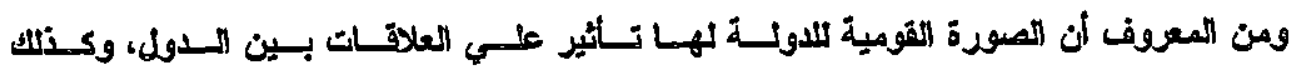

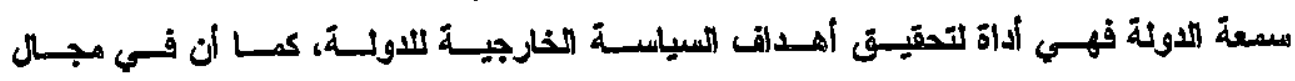

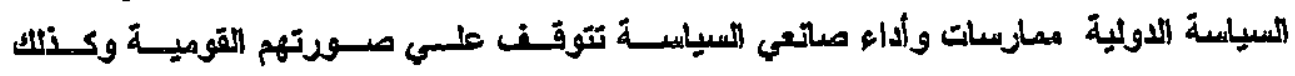

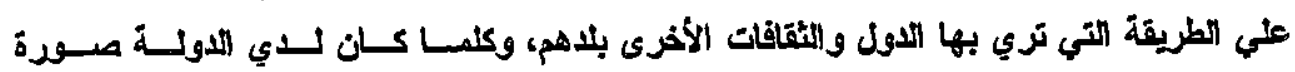

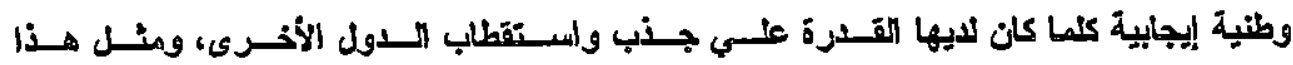

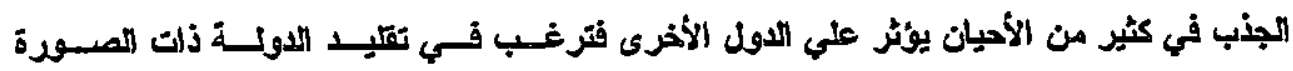

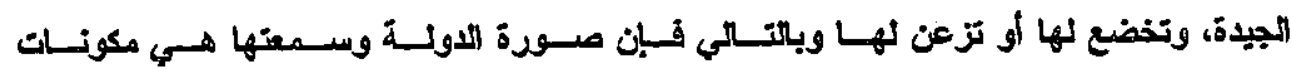

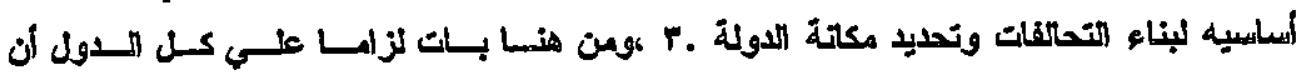

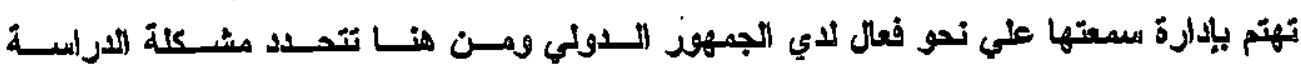

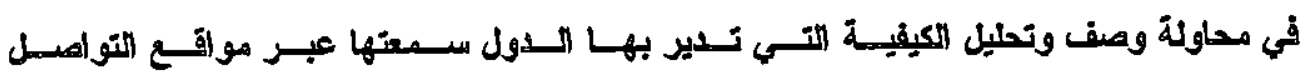

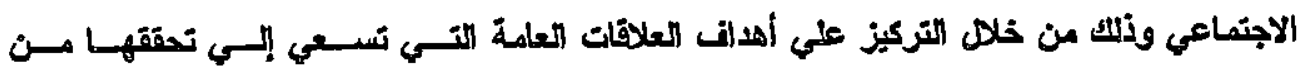

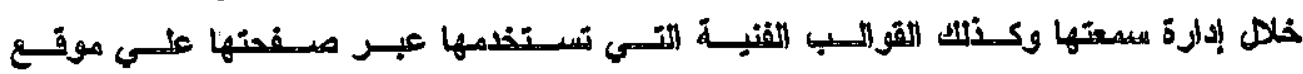


فاطمة الزهر اءء سعد مخمد طهة . دور العلاقات اللعامة في إدارة سمعة الادل عبر وسائل التواصل الاجتماعي"دراسة تحليلية.

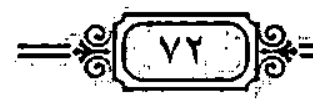

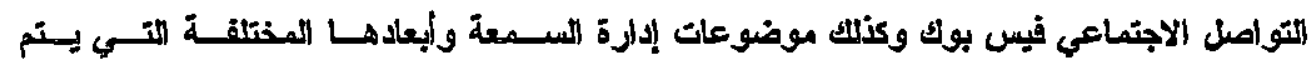

الاعتماد عليها .

أهداف الادراسة :

1 - التعرن علي أهداف العلاقات العامة الدولية للاول عينة الاراسة .

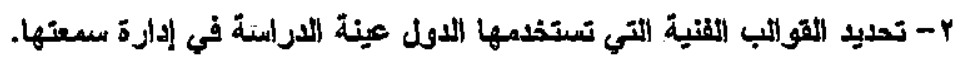

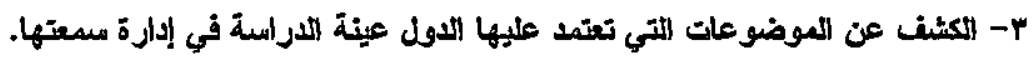

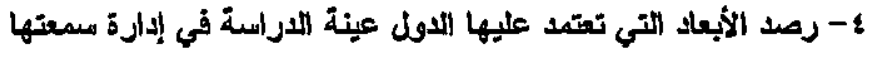
تساؤلات الاراسة :

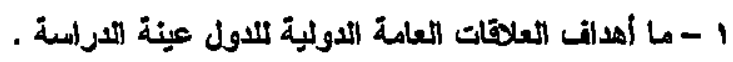

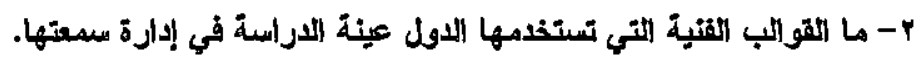

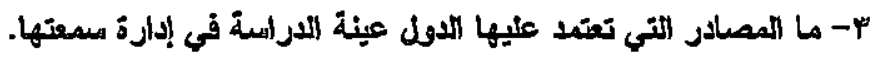
؟- المي أي مدي تعتد الدول عينة الارناسة على البعد العاطفي في الدارة سمعتها.

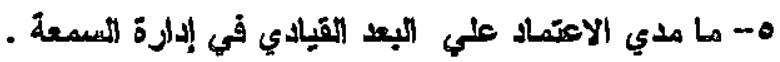

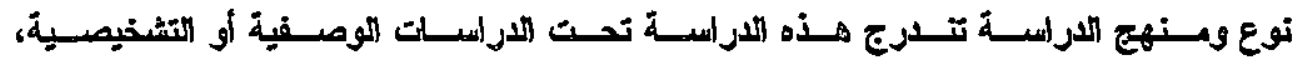

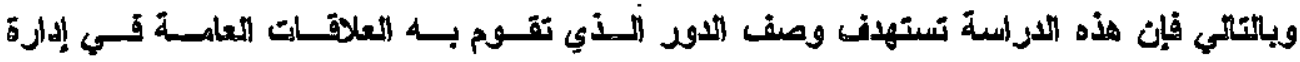

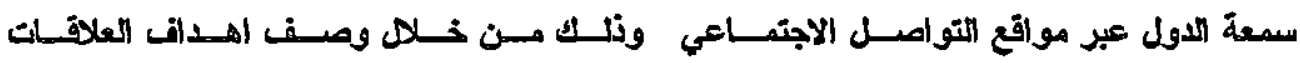

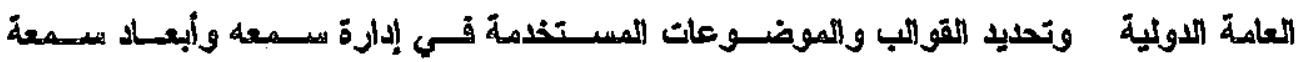

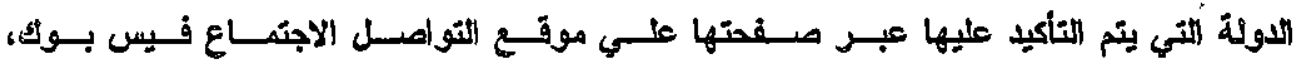

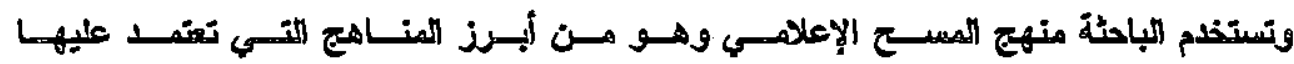

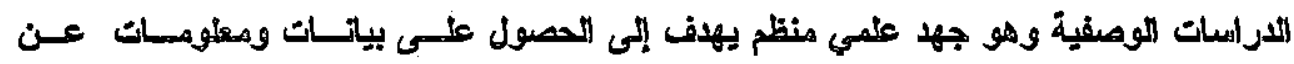
المأهن

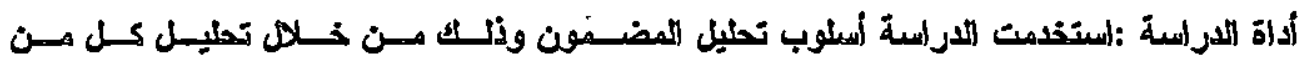

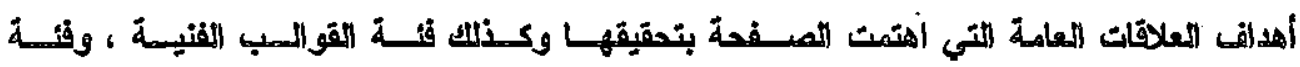
الموضوعات ، وفئة الأبعاد والتي شملت البعد العاطفي وبعد القيادة والبعد المادي. 
فاطمة الزهراء سعد محمد طه دود العلاقات العامة في إدارة سمعة الدول عبر

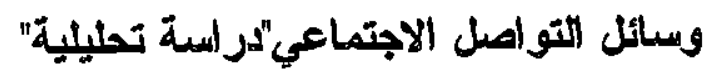
$=\frac{\mathrm{r}}{\mathrm{r}}$

أغلب المبادرات ذات جواتب اجتماعية وتتموية.

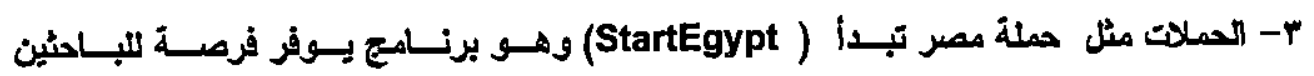

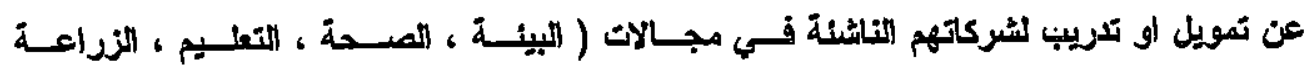

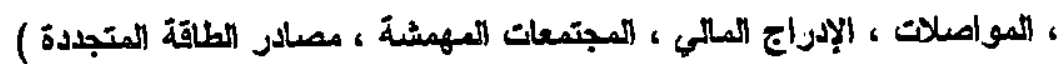

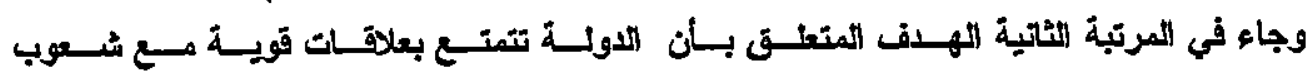

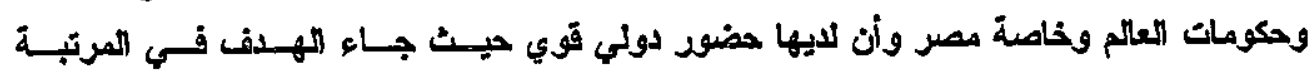

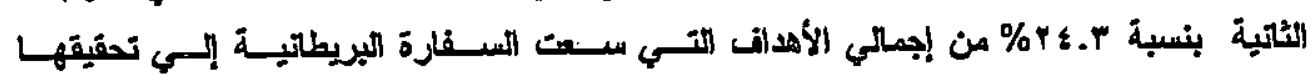

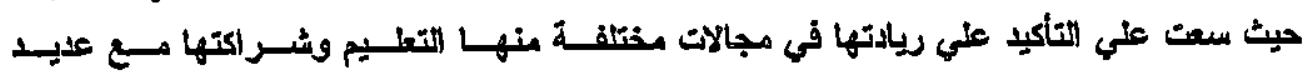

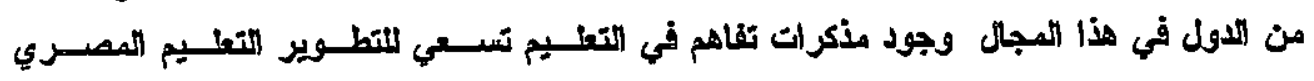

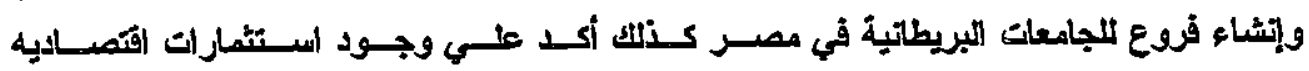

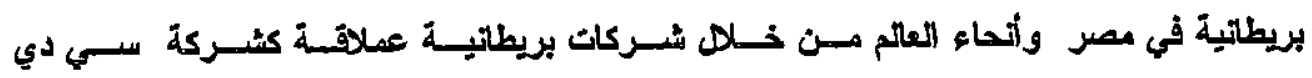

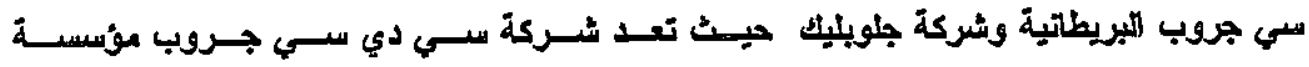

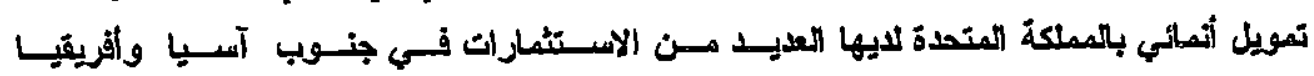

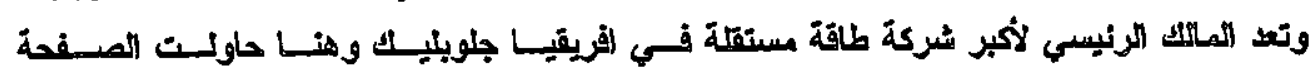

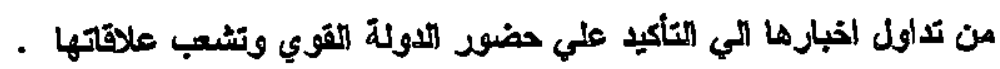

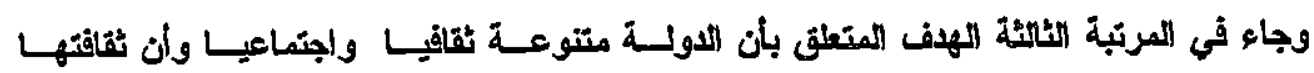

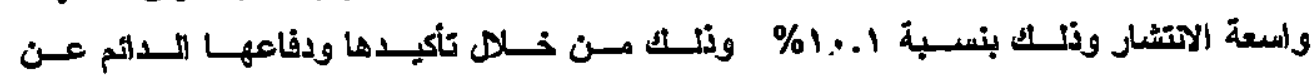

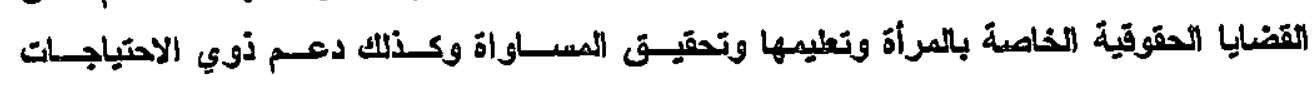

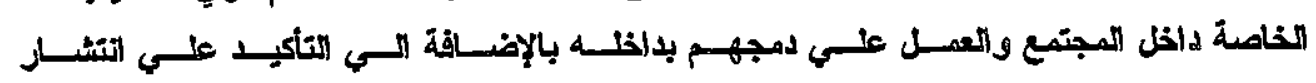

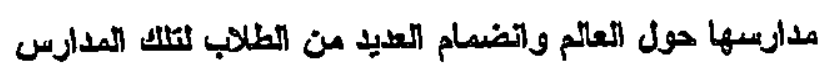

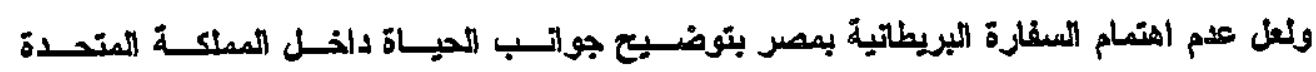

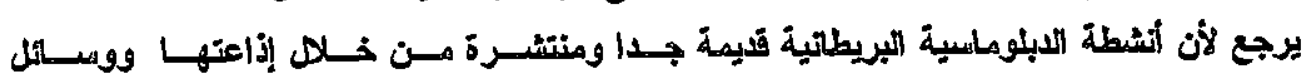

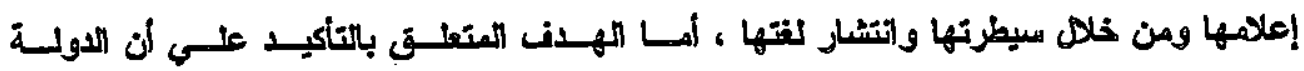

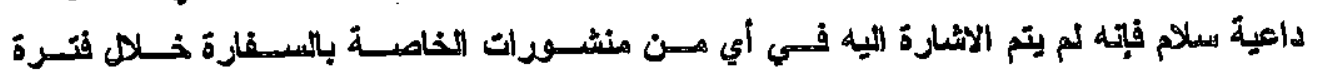


فاطمة الز هز اء سعد محفد طه دور العلاقات العامة في إدارة سمعة الاول عبر

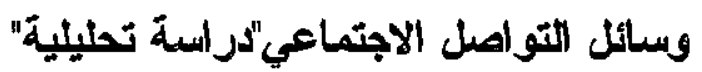
$=\frac{0}{2} v \varepsilon$

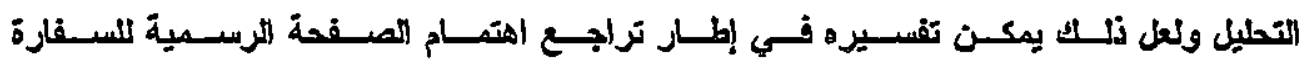

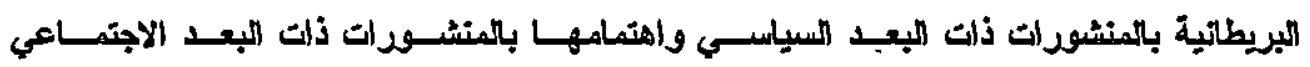
و التعليمي.

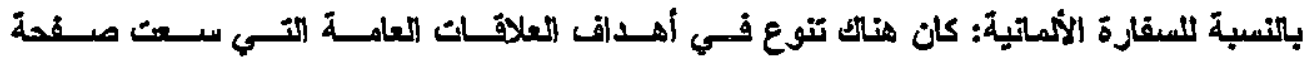

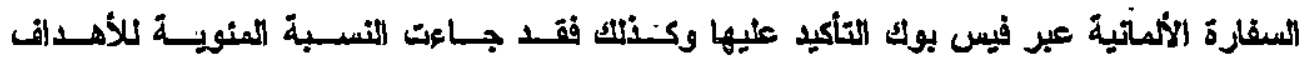

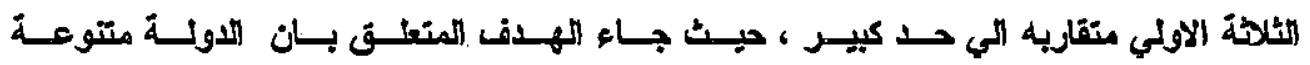

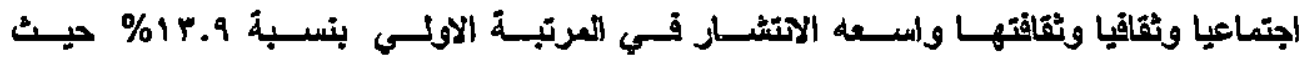

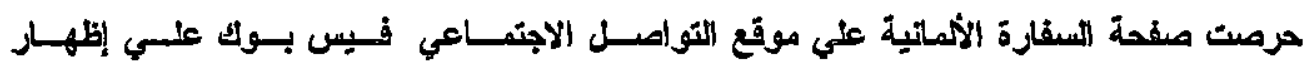

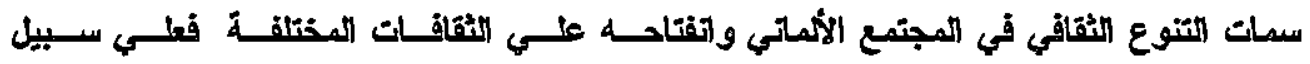

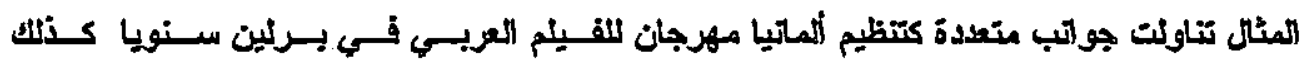

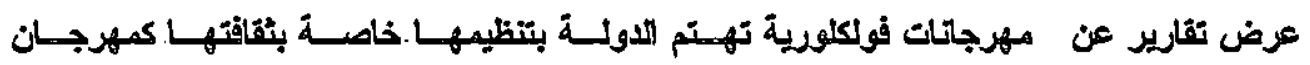

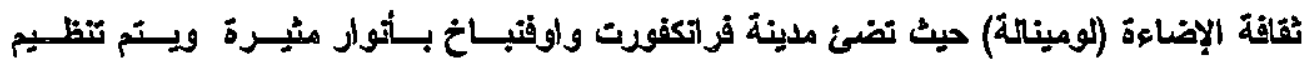

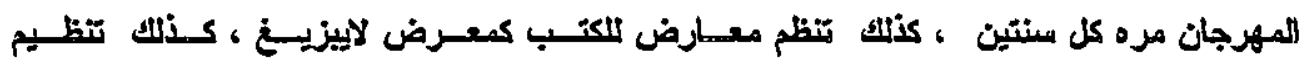

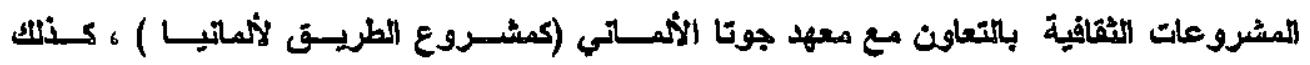

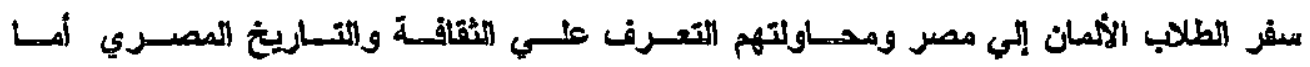

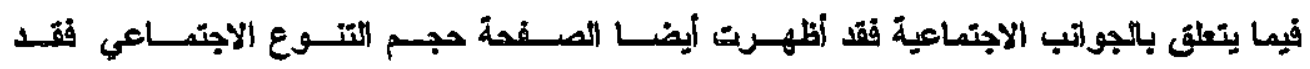

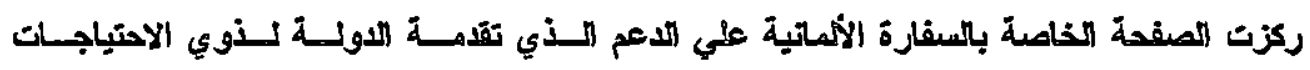

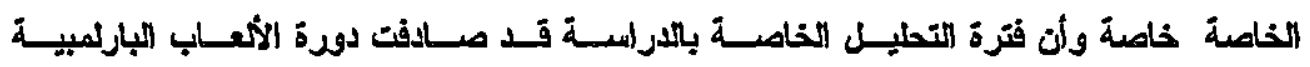

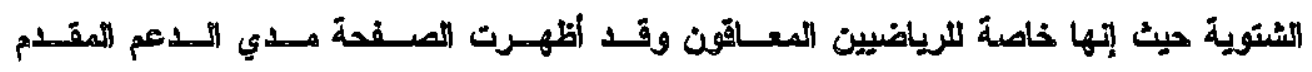

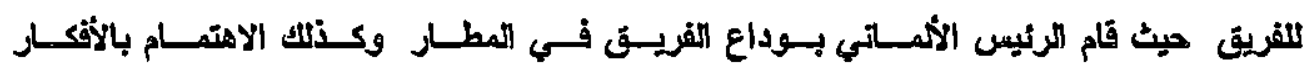

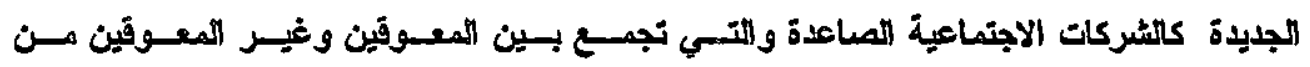

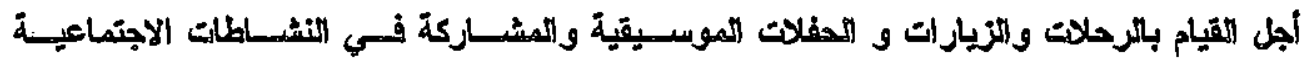

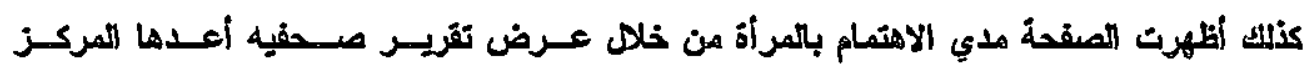

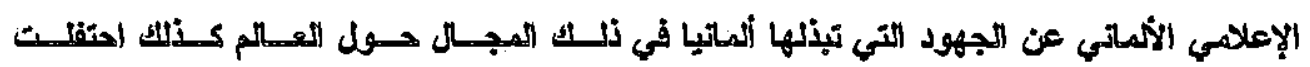


فاطمة الزهراءه سعد محمد طه دور العلاقات العامة في إدارة سمعة الاول عبر وسائل التواصل الاجتماعي"دراسة تحليلية"

$=80$

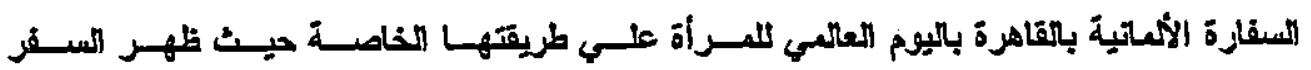

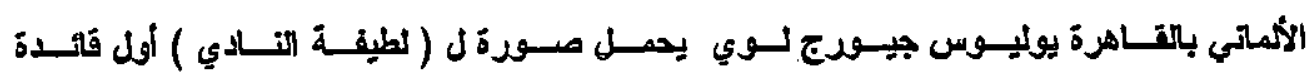

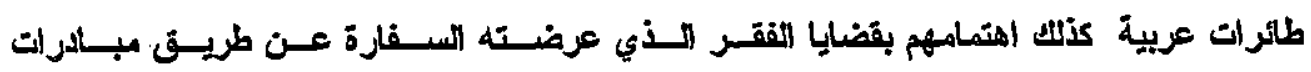

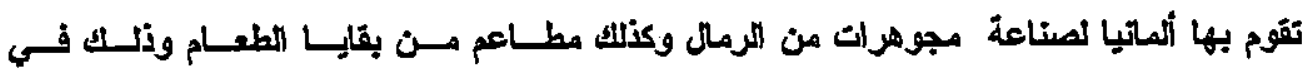

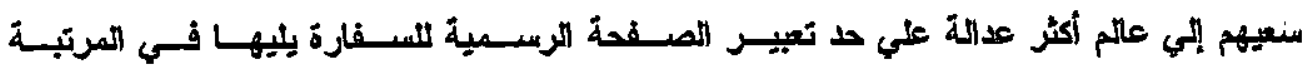

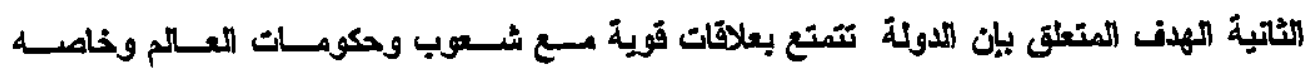

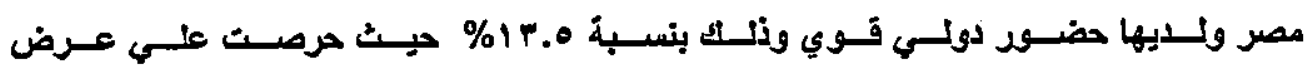

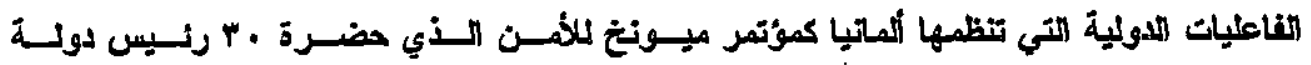

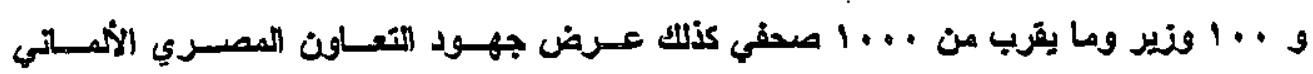

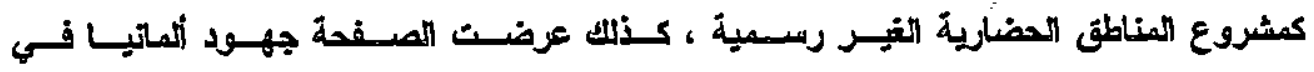

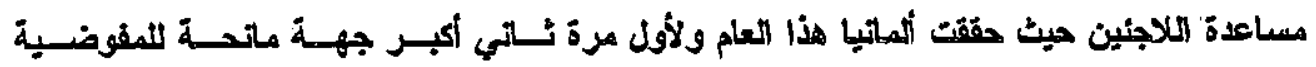

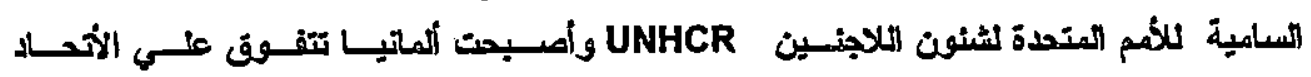

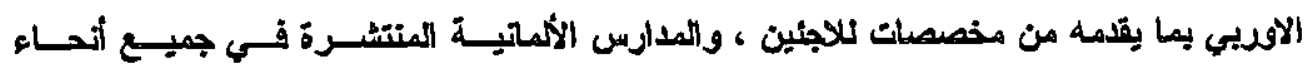

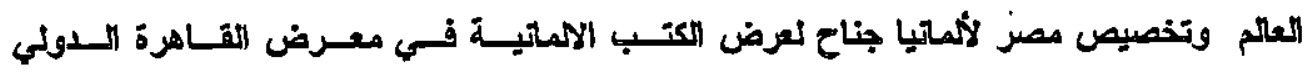

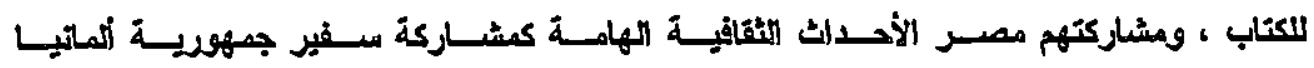

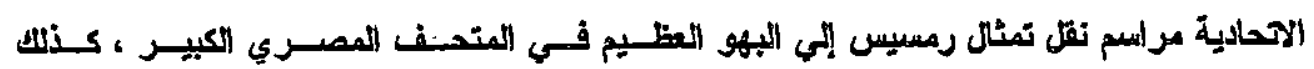

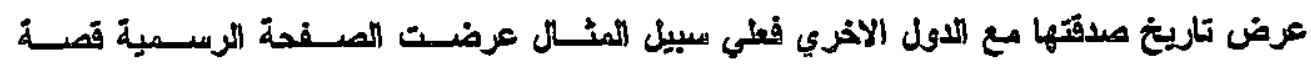

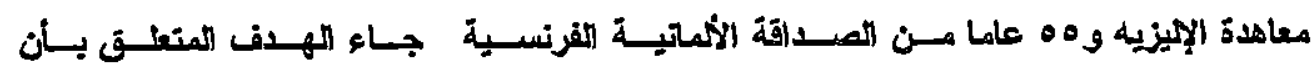

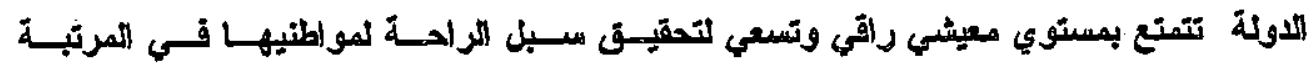

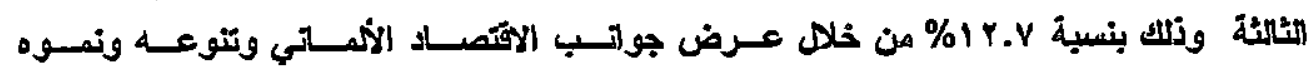

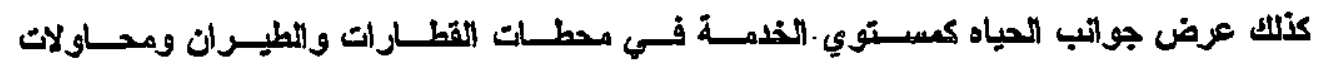

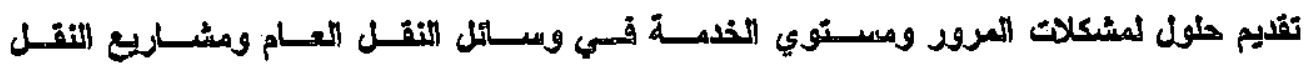

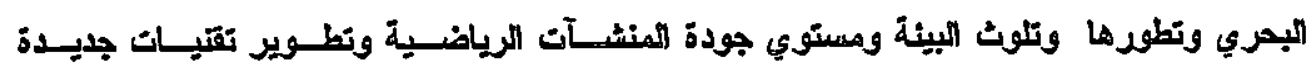

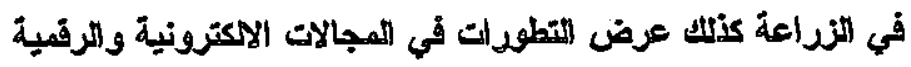


فاطمة الزهر اء سعد محمد طه دود العلاقات العامة في إدارة سمعة الاول عبر

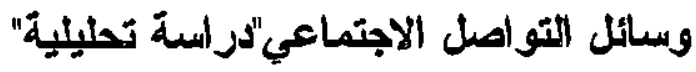
$=87$.

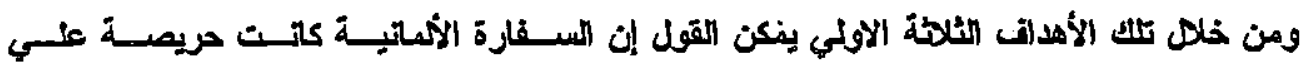

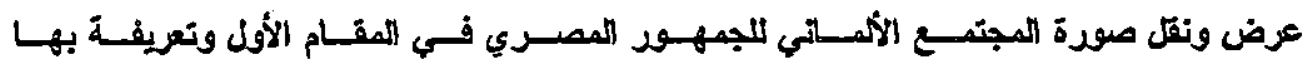

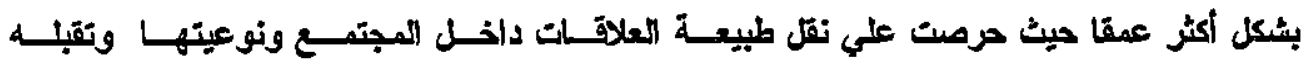

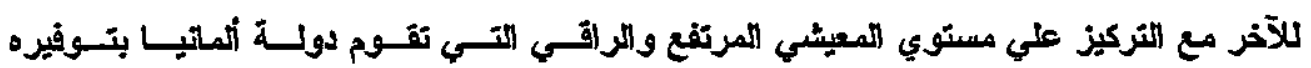

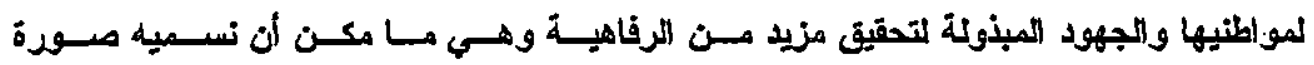

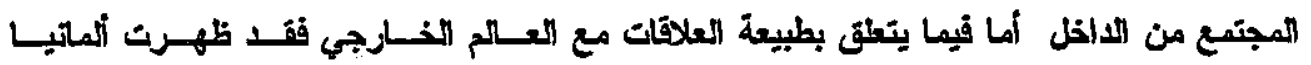

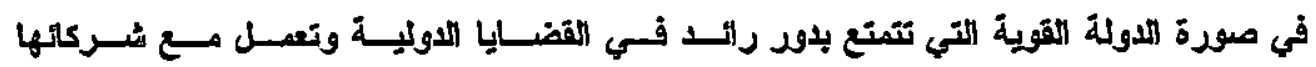

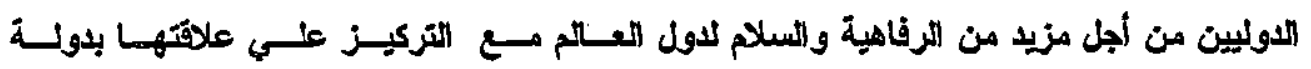

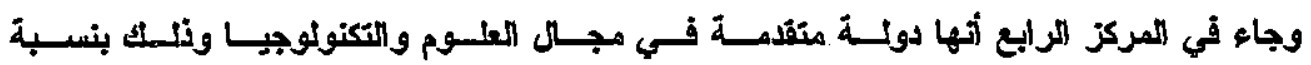

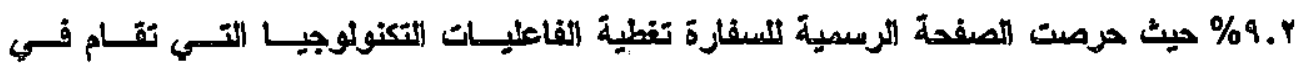

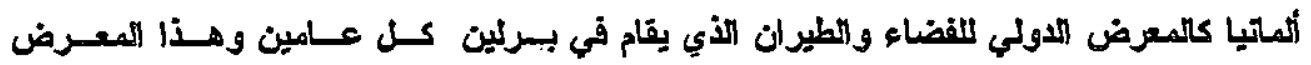

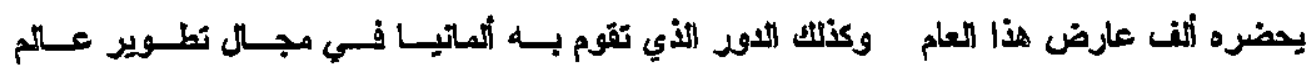

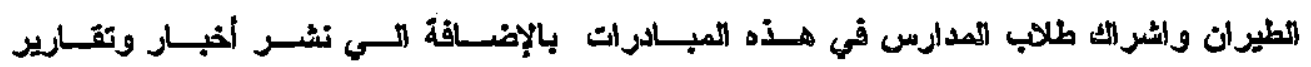

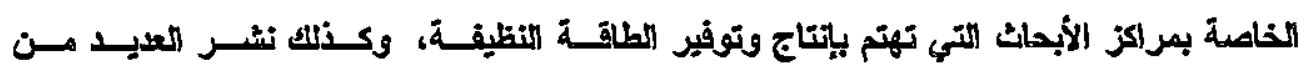

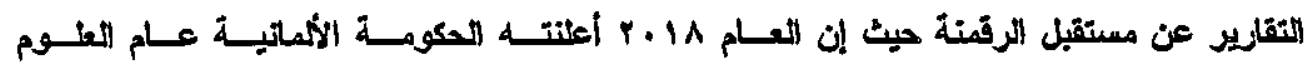

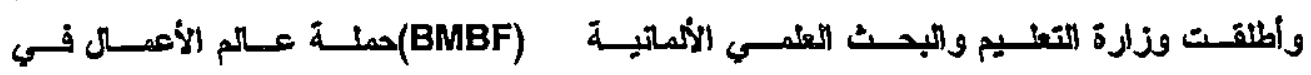

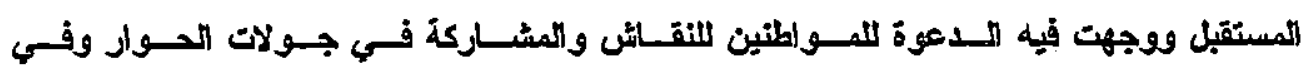

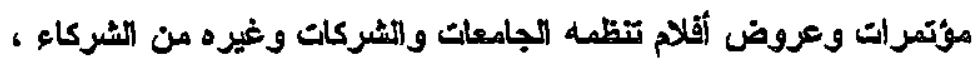

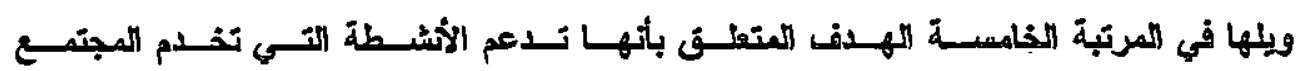

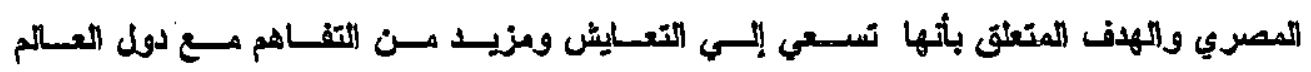

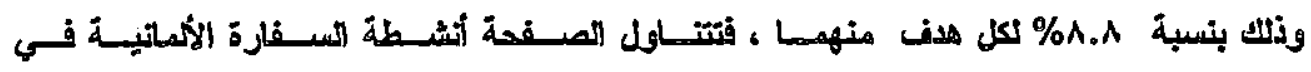

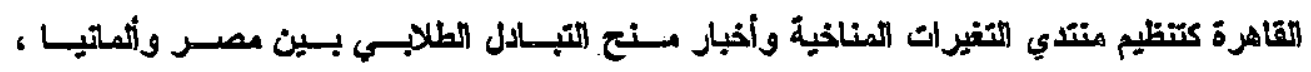

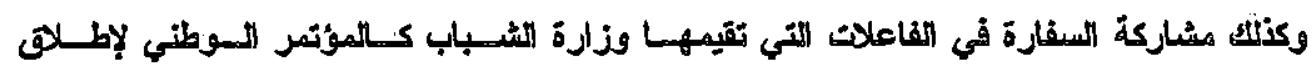


فاطمة المزهز اءع سعد محمد طه دور العلاقات العامة في إدارة سبمة الدول عبر وسائل التو اصل الاجتماعي"دراسة تحليلية"

$=\frac{0}{\mathrm{CVV}}$

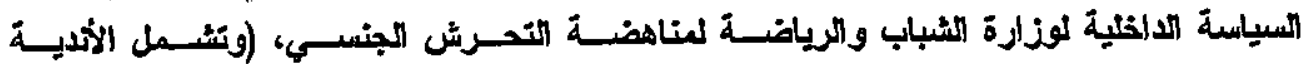

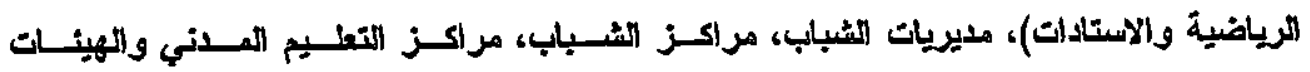

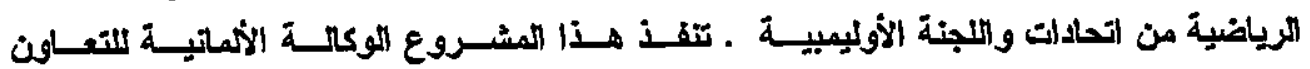

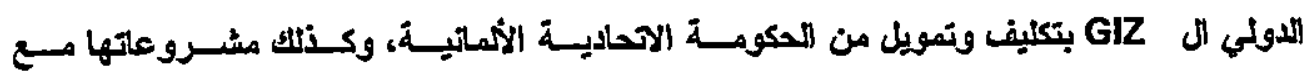

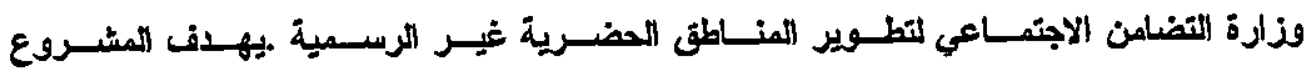

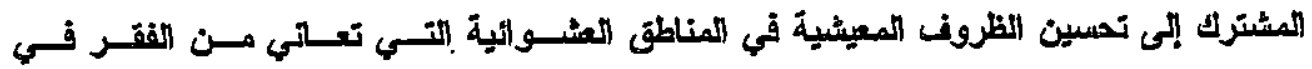

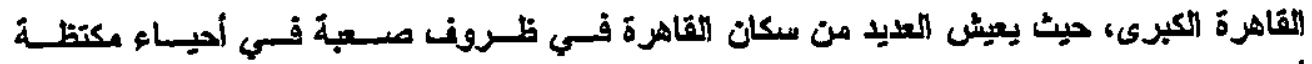

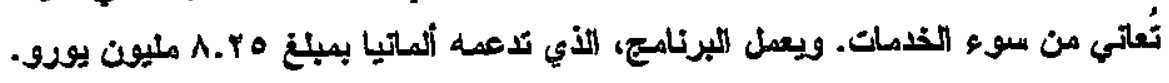

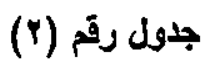

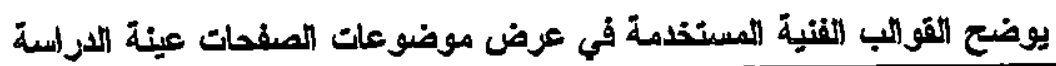

\begin{tabular}{|c|c|c|c|c|}
\hline \multicolumn{4}{|c|}{ الاوية } & \multirow[t]{3}{*}{ القوالب. الأنتية العستخلمة في عزض الموضوعات علي الصلمة } \\
\hline \multicolumn{2}{|c|}{ تلمتيا } & \multicolumn{2}{|c|}{ بريطاتيا } & \\
\hline$\%$ & $\%$ & $\%$ & ك & \\
\hline 17.1 & is & YY.E & $Y$. & حبر \\
\hline ry.1 & r & Pi.Y & ro & تقرير \\
\hline A. 9 & 1. & 0.0 & 8 & مقطع فيليو \\
\hline PY.1 & $r q$ & $1 . .9$ & $\wedge$ & صوره وتبليق \\
\hline- & - & 0.0 & $t$ & بيان محفي \\
\hline$\cdots 4$ & 1 & $1 . t$ & 1 & إعلان \\
\hline- & - & 1.1 & 1 & تعلئ \\
\hline 1.1 & $r$ & - & - & متّل \\
\hline 0.1 & 1 & - & - & إضافة لحاثت \\
\hline Y.Y & $r$ & - & - & 10: \\
\hline
\end{tabular}


فاطمة الزهراء سعد محمد طه دور العلاقات العامة في إلارة سمعة الدول عبر وسائل التواصل الاجتماعي"دراسة تطيلية" $=\frac{9}{V 1}$

\begin{tabular}{|c|c|c|c|c|}
\hline- & - & 1.9 & $\Lambda$ & القوجراف \\
\hline - & - & Y.Y & $r$ & بث مبائر \\
\hline $1 \ldots$ & $11 \%$ & $1 \ldots$ & Vr & العبموع \\
\hline
\end{tabular}

الولا بالنسبة للسفارة البريطاتية :- البعرعة

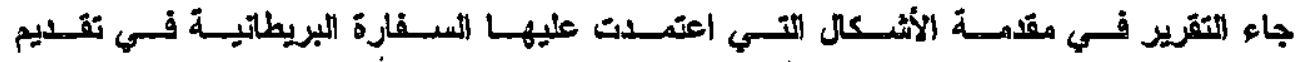

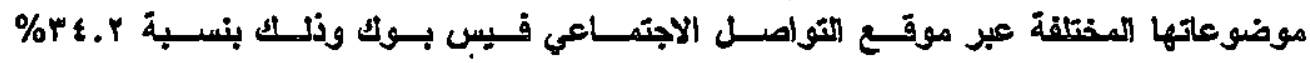

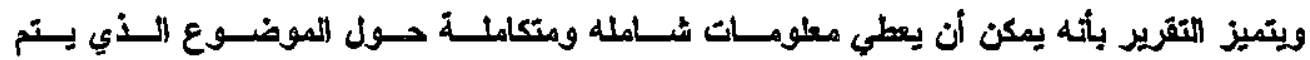

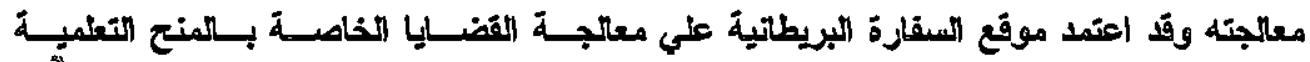

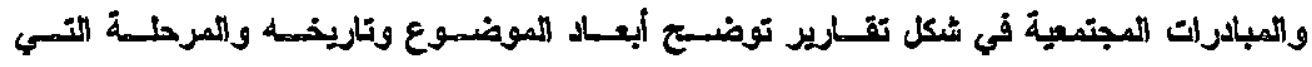

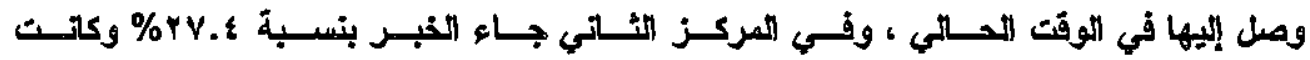

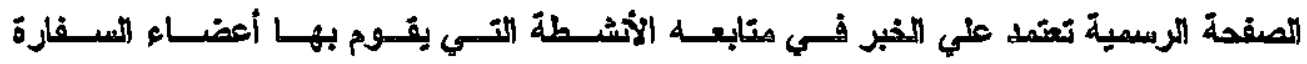

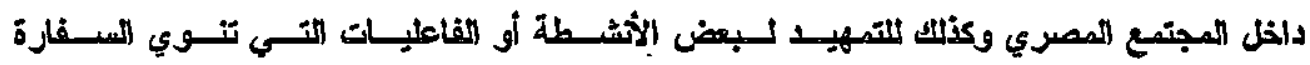

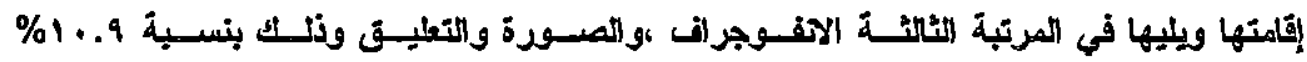

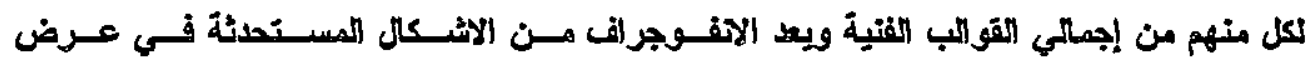

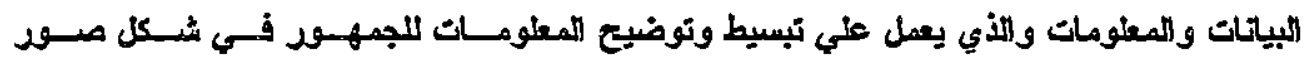

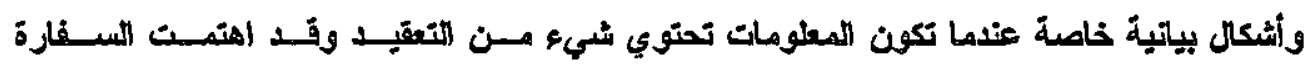

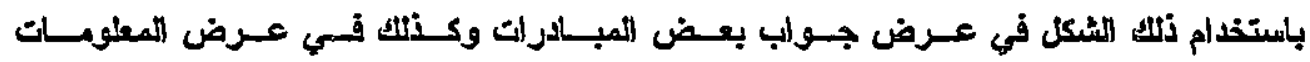

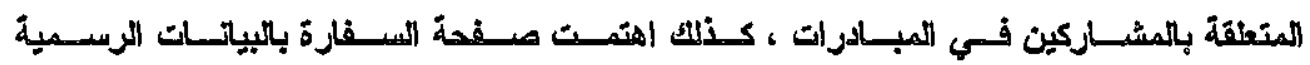
وكاتت نسبتها ه. 0\% أما فيعا يتعلق بالسفارة الألماتية :-

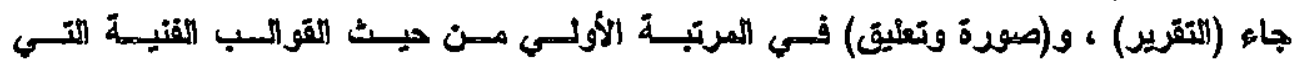

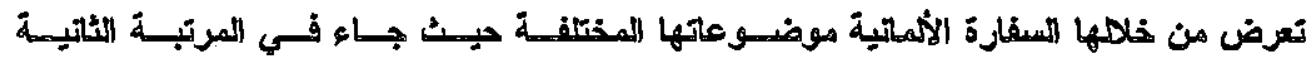

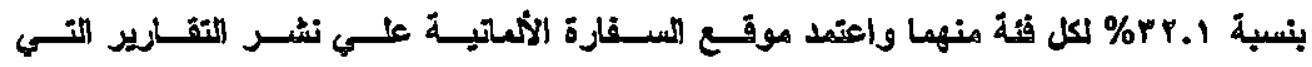

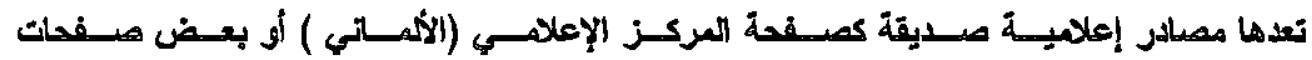

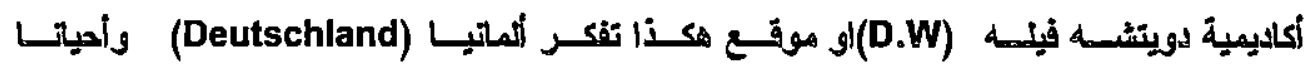


فاطمة الزهر اء سعد محمد طاهل دور العلاقات العامة في إلدارة سمعة الدول عبر وسائل التو اصل الاجتماعي"دراسة تحليلية"

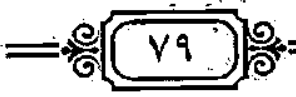

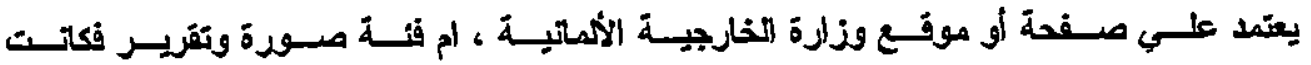

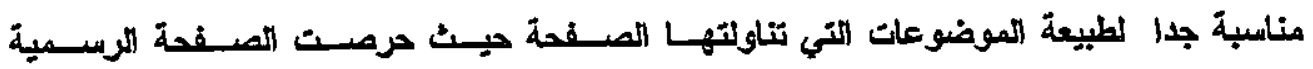

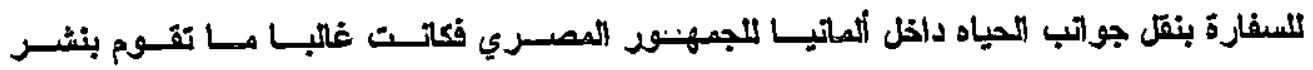

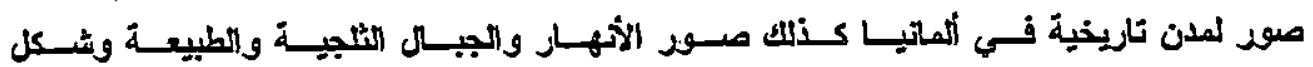
المنشآت الحايثة واتتظام المرود وأهم خصائص البنية التحتية الالماتية

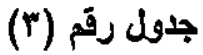

يوضح الموضوعات التي تناولتها الصفحة الترسمية للسفارات عينة اللدراسة 
فاطمة للزهز اءء سعد محمد طه دور العلاقات العامة في إدارة سمعة الاول عبر

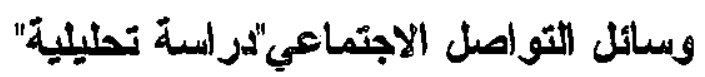

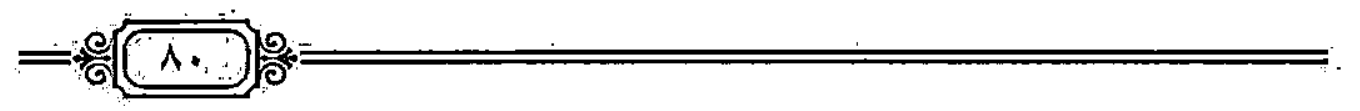

\begin{tabular}{|c|c|c|c|c|}
\hline \multicolumn{4}{|r|}{ الاولية } & \multirow[t]{3}{*}{ الموضوعات التي تثاولتها التصفحة الرسمية للسفارة } \\
\hline \multicolumn{2}{|r|}{ ألماتيا } & \multicolumn{2}{|c|}{ بريطلنيا } & \\
\hline$\%$ & s & $\%$ & ك & \\
\hline .14 .1 & rV & Y. & $\varepsilon$ & سياسية \\
\hline A.Y & iv & 17.9 & 28 & اجتماعية \\
\hline Q.V & $\gamma$. & $1 . .9$ & 18 & وقتصادية \\
\hline$\ldots 0$ & 1 & 1.1 & 3 & دينية \\
\hline Y.r & 10 & 8.7 & 11 & تكنولوجية \\
\hline 1.0 & $r$ & $r$ & 0 & قاتونية \\
\hline$r .9$ & $\wedge$ & PY.E & 37 & تعليمية \\
\hline $9 . Y$ & 19 & I.r & 2 & ثلثافية \\
\hline A.V & 11 & 1.1 & 3 & قنون \\
\hline 7.1 & 18 & $1 . . r$ & 17 & رياضة \\
\hline- & . & $t .1$ & 8 & صحية \\
\hline Ir.1 & ro & & & سياحية \\
\hline 9.7 & $r$. & $1 . r$ & $r$ & تاريخيه \\
\hline 1.0 & $r$ & Y.r & 12 & حقوقي \\
\hline Y.t & 0 & $r$ & 0 & خدمي \\
\hline$Y .9$ & 7 & 1.1 & 3 & بيئي \\
\hline$\ldots 0$ & 1 & Y.\& & 4 & أمني \\
\hline $1 \ldots$ & $r .9$ & 10 & 180 & المجموع \\
\hline
\end{tabular}


فاطمة الزهر اءغ سعد محمد طه دود العلاقات العامة في إدارة سمعة الاول عير

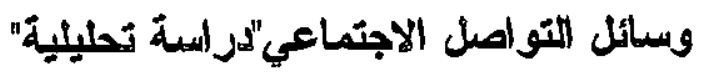
$=\frac{\mathrm{C}}{\mathrm{a}}$ (1)

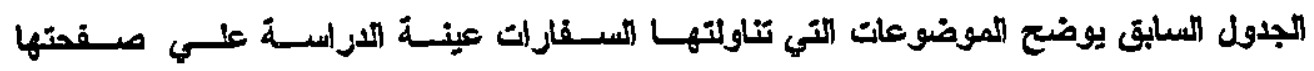

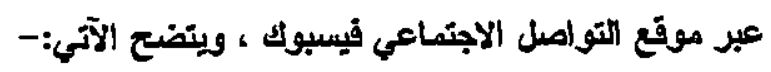

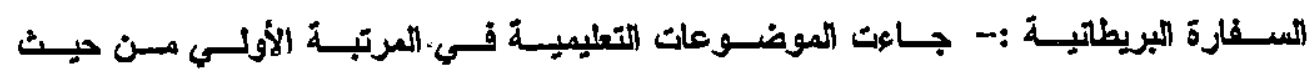

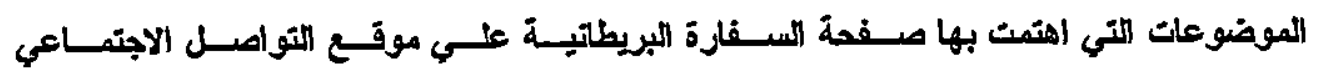

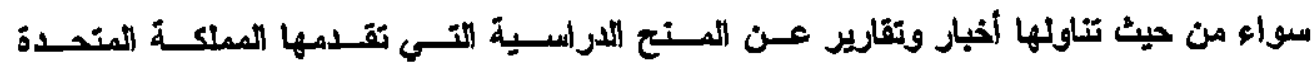

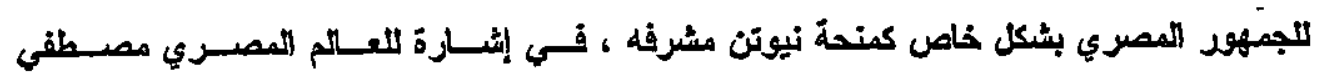

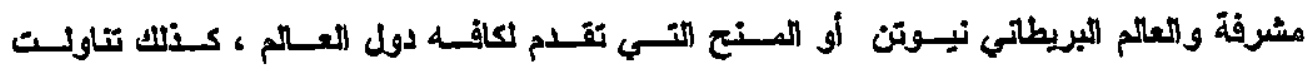

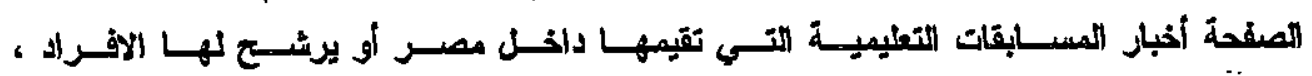

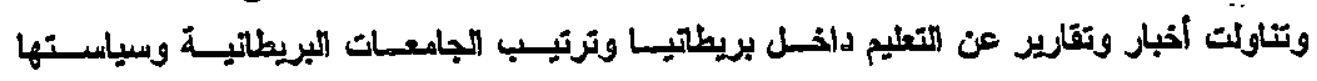

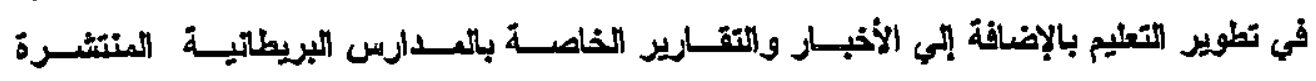

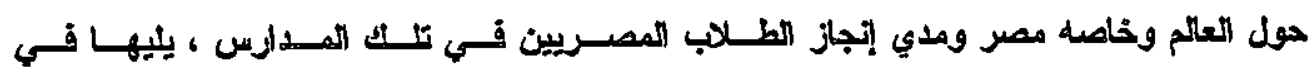

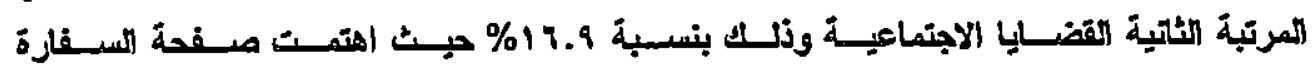

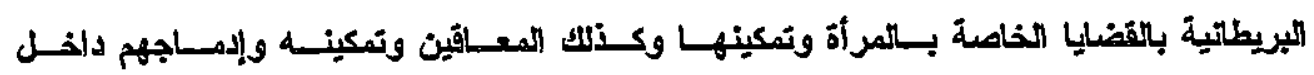

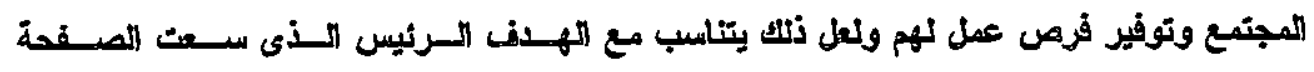

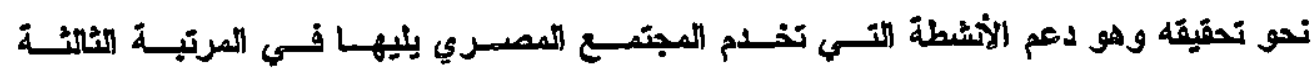

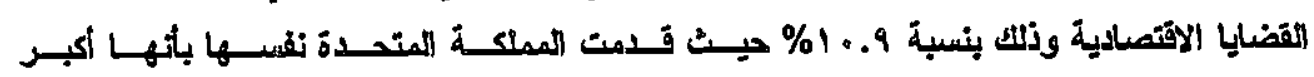

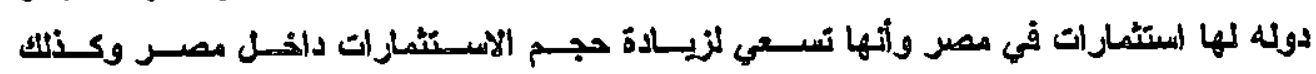

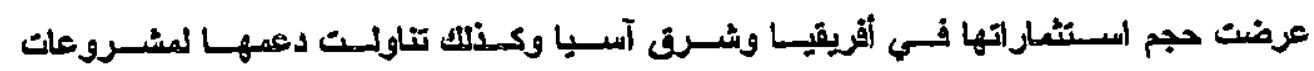

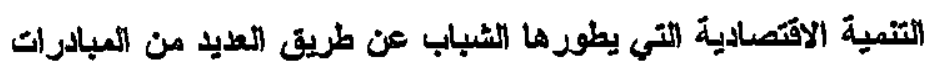

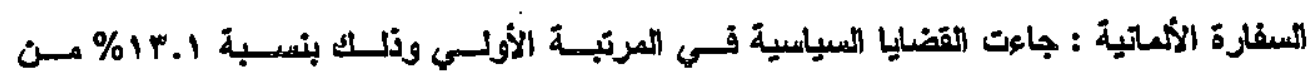

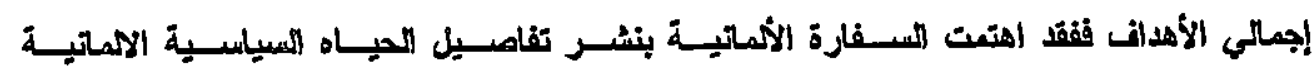

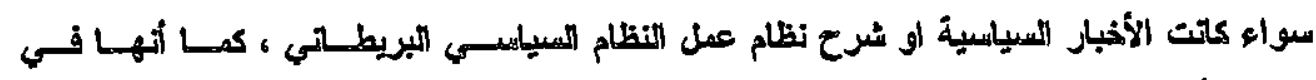

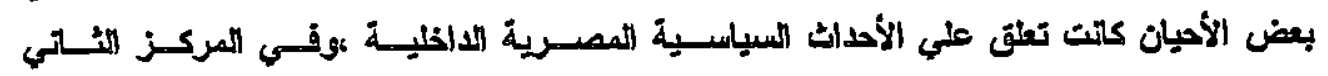

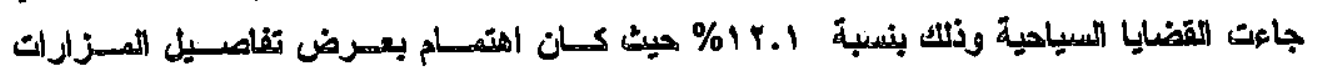


فاطمة الزهر اءع سعد محمد طه دور العلاقات العامة في إلارة سمعة الاول عبر

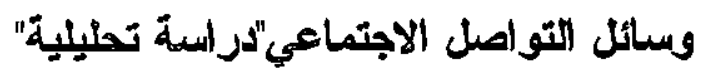

\section{$=$ (ir}

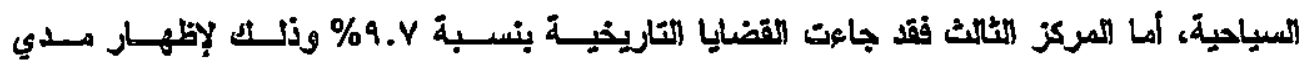
عراقة وحضارة الاولية الألماتية

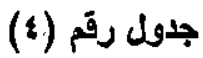

يوضع البعد العاطقي لإدارة سمعة الدول عينة الدراسة لادي الجمهور المصرني عبر موقع التواصل الاجتماعي فيس بوك

\begin{tabular}{|c|c|c|c|c|}
\hline \multicolumn{4}{|c|}{ إلدوأله } & \multirow[t]{2}{*}{ البعد العاطفي لإدارة المسمعة } \\
\hline \multicolumn{2}{|c|}{ ألماتيا } & \multicolumn{2}{|c|}{ بريطاتيا } & \\
\hline$\%$ & 4t & $\%$ & ك & \\
\hline or.A & $r \wedge$ & Y.9 & Yr & حب الاوىلة \\
\hline$Y \& . Y$ & Ye & $\varepsilon r$ & 89 & احترام الاولة \\
\hline IY.0 & 9 & 17.1 & 11 & ألثقة في الدولة \\
\hline $1 \ldots$ & Vr & $1 \ldots$ & 79 & المجموع \\
\hline
\end{tabular}

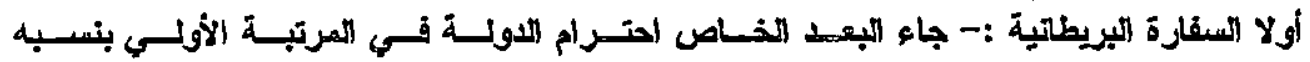

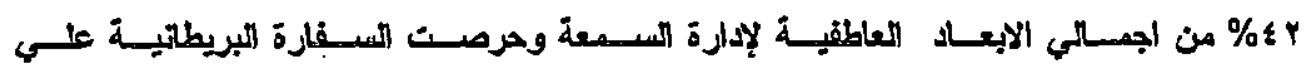

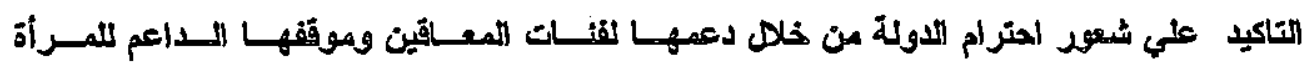

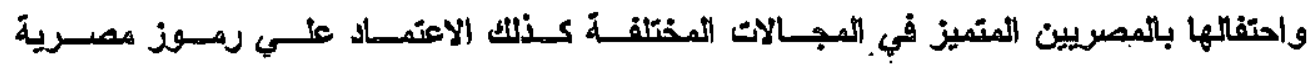

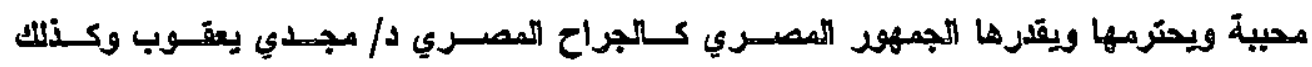

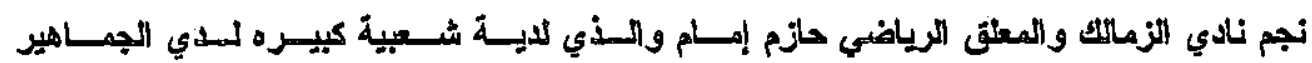

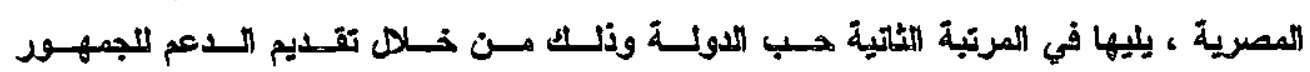

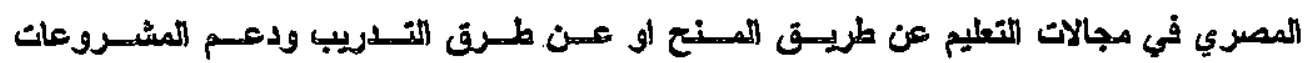

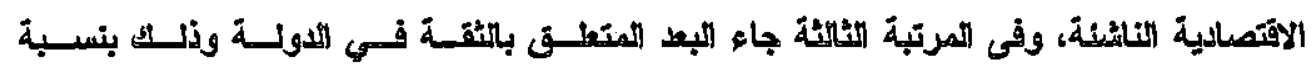


فاطمة الزهز اء سعد محمد طه دور العلاقات العامة في إدارة سمعة الدول عبر

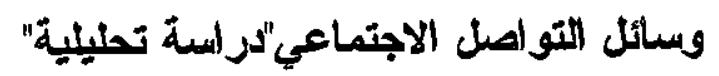
$=\sqrt{\mathrm{ar}}$

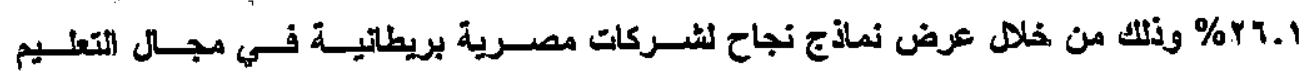
والأتصاد .

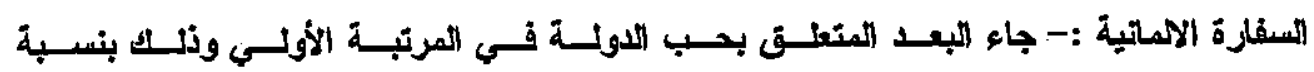

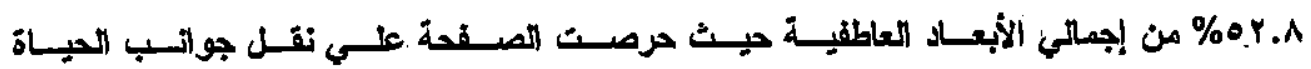

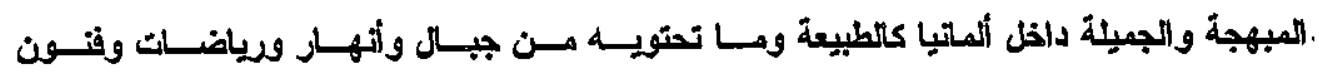

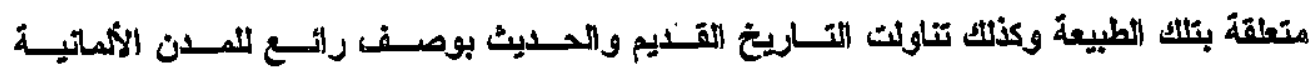

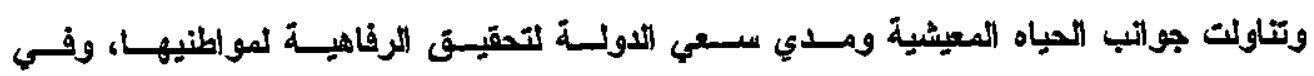

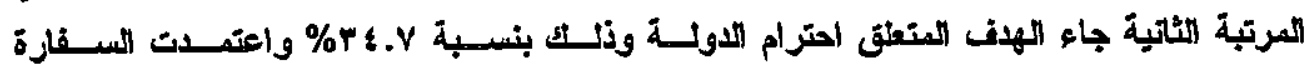

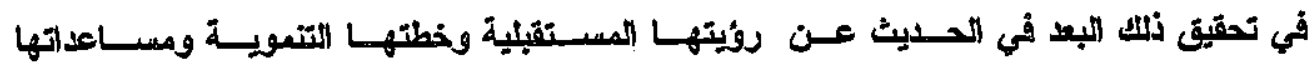

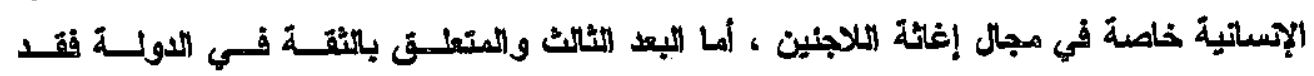

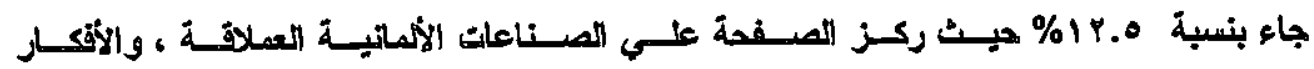

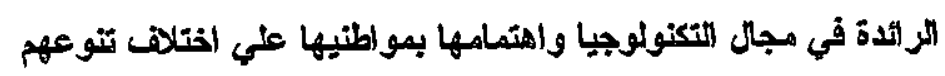
جدول رقم (0)

يوضح البعد المتعلق بالقيادة لإدارة سمعة اللدول عينة اللدراسة عبر صفحتها على موقع التواصن

\begin{tabular}{|c|c|c|c|c|}
\hline \multicolumn{5}{|r|}{ "البع المتطلق بالقيادة في الثارة السععة الاجتماعي } \\
\hline \multicolumn{2}{|c|}{ ألمتيا } & \multicolumn{2}{|c|}{ | بريطاتيا } & \\
\hline$\%$ & 4 & $\%$ & 4 & \\
\hline v. & 8 & 4.8 & $r$ & الدولة لاي قياداتها كاريزما وجانيبية \\
\hline $\overrightarrow{r v}$ & $r$ & 9 & iv & الدولة نعمل عي توصيل رؤية جذابة عن اللاولة \\
\hline$\$ 4.7$ & $r$ & YA.9 & $i r$ & تالر الاولة بطريقة جيدة \\
\hline$\pi$ & $v$ & 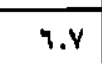 & $F$ & تحترم القانون الدولي \\
\hline$\ldots$ & $0 \varepsilon$ & $\overline{1}$ & \&0 & المجموع \\
\hline
\end{tabular}


فاطمة الزهر اء بسعد محمد طه دور العلاقات العامة في إدارة سمعة (لاول عبر

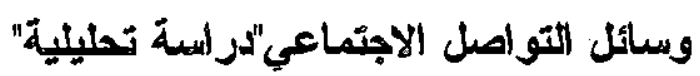

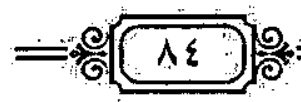

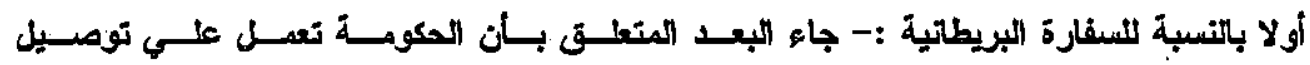

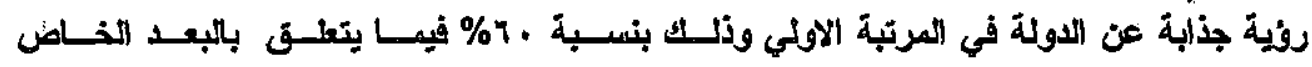

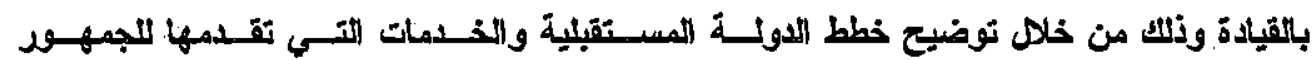

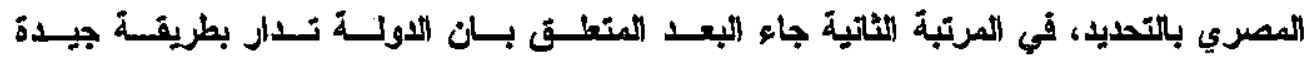

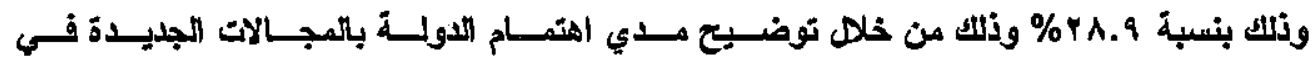

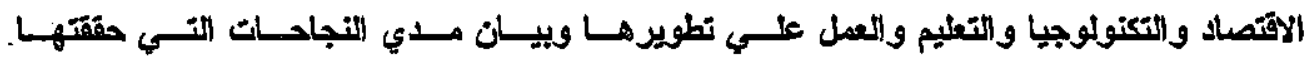

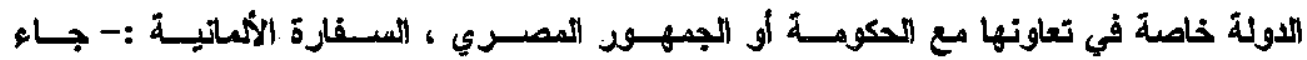

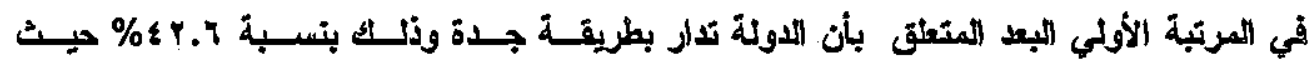

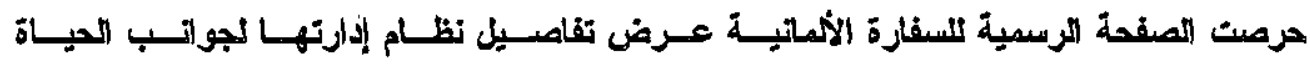

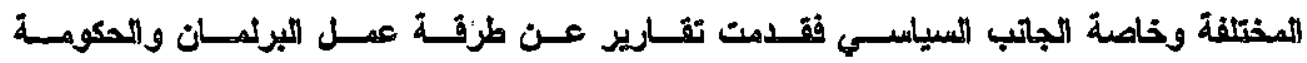

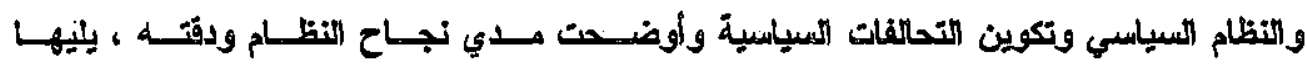

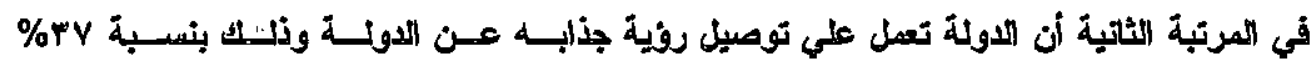

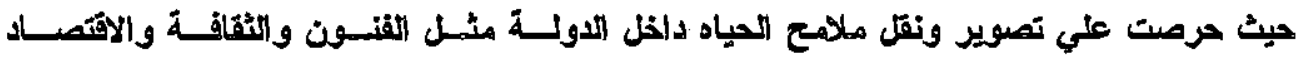

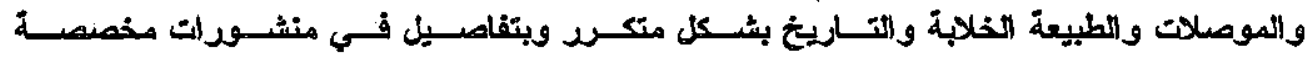

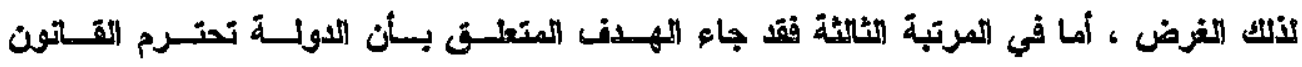
الاولي ، خاصة في مجالات اللديمقر اطية وحققة الإسان والحقاظ علي البيئة. 
قاطمة الزهر اءء سعد محمد طه دور العلاقات العامة في إدارة سمعة الدول عير وسائل التواصل الاجتماعي"دراسة تطيلية" 10

1- Dane M. Kiambi, and Shafer, Autumn,(2014) "Country Reputation Management: Developing a Scale for Measuring the Reputation of Four African Countries in the United States" Paper presented at the annual meeting of the Association for Education in Journalism and Mass Communication, Le Centre Sheraton, Montreal, Canada.

2 - Joachim Klewes, Robert Wreschniok,(2009): Reputation Capital: Building and Maintaining Trust in the 21st Century (Springer Science \& Business Media, new York) p:285

3 - Nadia Kaneva ,(2012) : Branding Post-Communist Nations: Marketizing National Identities in the "New" Europe ( Routledge, new York ) 